\title{
A Preliminary Study on the Construction of Innovation Laboratory for Agricultural Analysis
}

\author{
Wang Haifeng ${ }^{\text {a }}$, Liu Haixue ${ }^{\text {b, }}$, Zhu Wenbi ${ }^{c}$, Wu Huihuid \\ Center for Agricultural Analysis and Measurement, Tianjin Agricultural University, Tianjin 300384, China

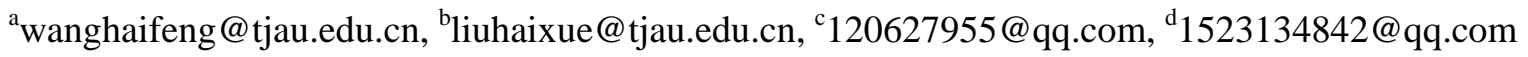 \\ *corresponding author
}

Keywords: Agricultural analysis; innovative laboratory; innovation ability; laboratory construction

\begin{abstract}
The construction of innovative laboratory plays an important role in the cultivation of innovation ability, innovation spirit and practical ability of undergraduates. In this paper, we further explore the ways of the construction of innovation laboratory for agricultural analysis through analysis of the concept, function and existing problems of the innovative laboratory.
\end{abstract}

\section{Introduction}

At present, China's economic development has entered a new normal, the total employment pressure still exists, and the employment situation of college graduates is still grim. Under the background of public entrepreneurship and innovation, the innovation and entrepreneurship education is of great practical significance for improving the quality of talent training and the quality of graduates' employment.

In 2015, the general office of the State Council issued an opinion on deepening the reform of innovation and entrepreneurship education in Colleges and universities. It is a general trend to deepen the reform of innovation and entrepreneurship education in Colleges and universities, to cultivate high-quality innovative talents, to promote the overall development of students and to promote the high quality of the students. As for our agricultural colleges and universities how to achieve high quality employment, as an experimental teacher, I thought of the establishment of innovative laboratory.

\section{The Concept of Innovative Laboratory}

The innovation laboratory is the platform of the innovation education of the school as the school, the important place to train the students' comprehensive practical ability and technical accomplishment; the students use their knowledge to carry on the important position of exploring and creating the activities; leading the students to acquire the practical activities through creative design and operational hands-on. Knowledge, skills, innovative consciousness and practical ability are important bases. Innovation includes conceptual innovation, knowledge innovation, technological innovation and so on. Conceptual innovation is the premise, knowledge innovation is the carrier, and technological innovation is the goal ${ }^{[1]}$.

\section{The Function of the Innovative Laboratory}

The construction of innovative laboratories should thoroughly change the traditional concept of laboratory construction, take key input, concentrate on construction, and set up a policy in place ${ }^{[2]}$. The significance is: is the need for quality education; the needs of cultivating innovative talents; the needs of students' individualized development; the needs of accelerating the process of education modernization education; the needs of the development of schools and teachers; the needs of school science and technology education. 


\section{Problems in the Laboratory}

In view of the problems of shortage of funds, low utilization rate of equipment and less experiment of students in the process of laboratory construction in Colleges and universities, combined with the National College Students' innovation and Entrepreneurship Program, the orderly construction of the laboratory is carried out around the training of talents, and the subjective initiative and complementation of the laboratory in the process of College Students' innovation experiment are discussed. Complementation, to achieve a win-win result of the students' innovation ability training and laboratory construction, and to provide a good platform for college students in the new era of more innovative ability to provide a good platform ${ }^{[3]}$.

\section{Principles of Agricultural Analysis And Innovation Laboratory}

The establishment of agricultural analysis and testing innovation laboratory is adhering to the principle of "strengthening the foundation, focusing on practice, cultivating ability and emphasizing innovation" ${ }^{[4]}$. The experimental teaching aims to set up an innovative experiment course for the agronomy majors oriented to agronomy, food science and engineering, biotechnology, environmental science, plant protection, aquaculture, marine fisheries, animal science and applied chemistry. The purpose is to effectively improve the utilization efficiency of laboratory resources and to create a better place for the undergraduate. The new talent training service will combine experimental teaching with students' Extracurricular Research and develop innovative experimental projects.

Its Characteristics And Innovation Points Are As Follows: Maximizing laboratory opening and combining students' innovative experiment. Taking the students as the main body and the teacher as the auxiliary "exploration method" teaching model, we adopt the concentric circle model of "doing middle school, learning to do, and doing the side learning", and carry out a variety of teaching methods, such as ability as the goal, teacher-student translocation interactive teaching, progressive teaching, and so on. The explanation of basic theoretical knowledge is permeated in the practice training process, and the theory is made in the theory of practice. Teaching, field teaching and experimental teaching are organically combined. The teaching process is lively but not boring, and improves the learning effect of students; The introduction of lectures from outside school experts, the establishment of an outside school practice base, the scope of the innovation laboratory, so that it is not confined to the laboratory of the University, and provides more space for the students to develop their talents; Transform the scientific research results into innovative experimental projects, constantly update the content of innovation experiment, make it knowledgeable, advanced and practical, increase the research components of the experiment, let the students apply their knowledge and skills independently, through consulting relevant literature and information, independent analysis, thinking, design and completion, in order to improve the study. Innovative consciousness and comprehensive ability to analyze and solve practical problems in agricultural production; In the new and open innovation experiment teaching mode, we should strengthen the vitality of the practical teaching link, make full use of modern educational technology and adopt multimedia simulation teaching, so that students can master the principle of method more easily, combine video, physical and animation, so that students can master the internal structure and operation of the instrument more easily and stimulate the students' initiative. Learning desire, to cultivate students' knowledge application ability, information acquisition and selection ability, hands-on practice ability and innovation ability ${ }^{[5]}$.

\section{Construction of Agricultural Analysis and Innovation Laboratory}

First of all, we need to satisfy the needs of innovative students, so that their innovative consciousness can be applied. Design a new teaching method of innovation experiment, publish innovative experiment teaching material, establish the practice base outside school, combine the students' innovation experiment and practice closely, increase the research component of the 
innovation experiment, let the students use their knowledge and skills, analyze and think independently and solve the practical problems of agricultural production.

\subsection{Standard Management.}

The construction of the innovation laboratory will be included in the development plan of the agricultural analysis and testing center and the annual work plan. At the end of the year, the work plan will be done well, the work plan for the next year will be written, and all the opportunities are used to instill innovative ideas for the students and to start their innovative thinking. On the basis of the opening of the original laboratory, we should further refine and manage the innovative laboratory by the special person, and formulate the rules and regulations of the innovative laboratory.

\subsection{Strengthening the Construction of Innovative Teachers.}

We should strengthen the training of the teachers, update the teaching content in time, and encourage the teachers to integrate the international academic frontier, the latest research results and the innovative practice experience into the experimental teaching, and promote the students' creative $^{[6]}$ through the learning of new and interdisciplinary subjects. We should thoroughly implement heuristic, deliberative and participatory teaching methods to cultivate students' curiosity, imagination, critical thinking and creative thinking. Take part in the relevant meetings of innovative and entrepreneurial work within and outside the school, instruct teachers to take advantage of weekends or cold and summer vacation time to go out to study, lead the students to visit the base or related enterprises, and actively participate in the research, study inspection and work exchange of the internal and external organizations.

\subsection{Perfecting the Curriculum System.}

On the basis of the original curriculum system, "innovation experiment" is implemented as a minor major, that is, through the construction and improvement of "innovation experiment" education, the students who are interested in participating in the innovative practice activities have set up a series of "innovative agricultural analysis and testing" project to provide a strong guarantee for the students' employment.

\subsection{Investment in Funds and Construction of Hardware Facilities.}

At present, the laboratory has built an experimental network platform, and made the corresponding experimental teaching courseware. Students can browse the network at any time to learn and download, which provides students with the opportunity to study independently. In order to facilitate students'self-study and truly participate in the interaction of innovative experiments, some educational resources (excellent courses, network courses, multimedia electronic teaching plans, syllabus, teaching rules and regulations, experimental equipment, etc.) in the laboratory are put on the central web page and virtual simulation experiment projects are being introduced to make students from simple. The passive transfer of knowledge into active participation and autonomous learning.

Students can answer questions and make an appointment experiment through the Internet. At present, the daily management of laboratories has been networked, improving the efficiency of experimental teaching management.

\subsection{Strengthen Training.}

The introduction of foreign teachers to the innovative laboratory education, to explore the establishment of outside the campus base, to improve the integration of experimental teaching and practical teaching, so as to improve the students' interest in innovation experiments, stimulate creative enthusiasm and improve the quality of training.

\subsection{Increasing Innovation and Entrepreneurship Service.}

In recent years, our center has undertaken more than 30 projects of innovation and 
entrepreneurship for college students. The results are displayed on the exhibition board to stimulate the innovative consciousness of the junior students; the main forms are the teachers' Forum. The main aspects are the selection of innovative projects, the discussion of the project that the teachers are interested in, the demonstration of the scientific research program, the solution of the problems in the process of scientific research, and the summary of the project; the technical training will carry out special training for some of the technologies needed in the project research, and the experience exchange in principle completes one to two projects. It is necessary to organize an experience exchange to play a role in knowledge sharing, common progress and teamwork. The students' professional innovation and entrepreneurship projects are given positive guidance and support. These projects, which are closely related to the actual life, give students positive guidance and help, lead the students to carry out more in-depth research, and solve practical problems for the enterprises.

\section{Summary}

The construction of agricultural analysis innovation laboratory will continue to develop in a deep direction with the aim of cultivating students' innovation concept, innovation consciousness, innovation spirit and innovation ability.

\section{Acknowledgements}

This work was financially supported by the university teacher education reform and innovation guidance development projects of TJAU (20171009 and 20170402) and 2018 innovative and entrepreneurship laboratory project of TJAU.

\section{References}

[1] D.Y. Chen. Experimental Technology and Management, Vol. 1(2005), p9-12 (in Chinese).

[2] X.Y. Huang, H.C. Wang, X.Y. zhaou. Laboratory Research and Exploration, Vol. 36(2017), p267-270 (in Chinese).

[3] ZH.X. Ren, G.F. Wei, Z.SH. Xin. Heilongjiang Education (Theory and Practice), Vol. 12(2016), p18-19 (in Chinese).

[4] W.T. Wang, H. Zhao, R.J Liu. Experimental Technology and Management, Vol. 33(2016), p30-32 (in Chinese).

[5] ZH.R. Yuan, Y.Y. Han, Q. Weng. College Biology Teaching Research (Electronic Version), Vol. 6(2016), p54-56(in Chinese).

[6] Y.J. Ji, J. Yang, H.ZH. Wang. Experimental Technology and Management, Vol. 26(2009), p134-136 (in Chinese). 